\title{
Gestión de la información: dilemas y perspectivas
}

\author{
Coordinadoras Marta Lígia Pomim Valentim (UNESP/Brasil) \\ y María Cecilia Corda (UNLP/Argentina)
}

La gestión de la información puede ser comprendida bajo dos enfoques distintos: el primero relacionado al profesional de la información como gestor de una unidad de trabajo, en este caso pudiendo ser una red, sistema, unidad o servicio de información; el segundo relacionado a procesos y actividades en una organización, correspondiente a cualquier segmento económico: industrial, comercial, financiero, jurídico, científico, educativo, tecnológico, sindical, de salud, entre otros.

La gestión de la información, enfocando la acción del profesional de la información como gestor, involucra la elaboración de planificaciones, políticas, programas y proyectos que serán desarrollados en el ambiente de trabajo de modo que el equipo como un todo pueda aprovechar la gestión de datos e información que subsidien el proceso decisorio en el desarrollo de actividades informacionales, o sea, la gestión de la información será realizada para el propio consumo del equipo informacional.

También, la gestión de la información ejercida como una de las funciones del profesional de la información en determinado segmento económico, se refiere al desarrollo de procesos y actividades informacionales que subsidian a los sujetos organizacionales en el desempeño eficiente, proporcionando más seguridad a los decisores y propiciando diferenciales competitivos que posibiliten a la organización mantenerse en el mercado en que actúa.

En los dos casos, la gestión de la información es esencial si el objetivo es obtener eficiencia de los procesos y las actividades y eficacia en los resultados a ser obtenidos.

Se entiende a la gestión de la información "[...] como un conjunto de actividades para prospectar, monitorear, seleccionar, filtrar, organizar, tratar, agregar valor y diseminar información, así como para aplicar métodos, técnicas, instrumentos y herramientas que apoyen este conjunto de actividades" (Valentim, 2007, p.18, traducción propia). Por lo 
tanto, la gestión de la información involucra todo el ciclo informacional, cuyo propósito es fundamentar las actividades y tareas desarrolladas por los sujetos organizacionales.

Las principales actividades de la gestión de la información implican: "[...] obtener un diagnóstico de las necesidades informacionales; mapear los flujos formales de información en los distintos sectores de la organización; prospectar, recoger, filtrar, monitorear, diseminar información de diferentes naturalezas; y elaborar servicios y productos informacionales, con el objetivo de apoyar el desarrollo de las actividades / tareas cotidianas y el proceso decisorio en esos ambientes" (Valentim, 2008, p.4, traducción propia).

Es evidente que la gestión de la información está relacionada con los flujos formales, es decir, a los datos e informaciones que de alguna manera están explicitados en algún soporte o sistema. Para comprender la complejidad de los flujos formales, se destacan los datos e informaciones estructurados: son sistematizados, organizados, tratados y están disponibles para su acceso; los estructurables: producidos por los propios sujetos organizacionales en los diversos sectores de la organización, pero sin selección, organización, tratamiento y acceso; y los no estructurados: son producidos por varios actores externos a la organización, y, por lo tanto, sin identificación, selección, filtración, organización, tratamiento y acceso (Valentim, 2002, p.8).

Varios tipos de información son objeto de atención de la gestión de la información, entre ellos se pueden mencionar los datos e informaciones: estratégicos, financieros, comerciales, estadísticos, gerenciales, tecnológicos, entre otros (Valentim, 2002).

Las actividades base de la gestión de la información abarcan: a) identificar demandas y necesidades de información; b) mapear y reconocer flujos formales; c) desarrollar la cultura organizacional positiva en relación al compartir y/o socializar la información; d) proporcionar la comunicación informacional de modo eficiente, utilizando tecnologías de información y comunicación; e) prospectar y monitorear información; f) recoger, seleccionar y filtrar información; g) tratar, analizar, organizar, almacenar información, utilizando tecnologías de información y comunicación; h) desarrollar sistemas corporativos de diferentes naturalezas, buscando el intercambio y uso de información; i) elaborar productos y servicios informativos; j) fijar normas y estándares de sistematización de la información; I) retroalimentar el ciclo (Valentim, 2004).

En este número especial de la revista Palabra clave, cuya temática se refiere a la gestión de la información, los lectores encontrarán textos que abordan las bases teóricas de gestión de la información; la interrelación entre la competencia en información y la gestión de la información en el contexto empresarial; la preservación de documentos archivísticos en ambiente digital como una actividad base de la gestión de la información; el ciclo de vida de documentos sonoros como una actividad base de la gestión documental y, por lo tanto, de la gestión de la información; la identificación de las necesidades informacionales de los usuarios, también como una actividad base de la gestión de la información; la gestión de riesgos en unidades de información; la gestión de perfiles de autores en repositorios institucionales; la gestión de la información aplicada a la medición de la producción científica y tecnológica institucional; el estudio de ambientes informativos en instituciones educativas; la gestión de la información aplicada a proyectos de extensión, 
en especial en una biblioteca popular; la temática gestión de la información presente en revistas brasileñas y argentinas; la relación entre gestión de la información y gestión documental en el ámbito de la archivología; y, por último, el comportamiento informativo en relación con el proceso de toma de decisiones.

iBuena lectura!

Marta Lígia Pomim Valentim (UNESP/Brasil)

\section{Referencias bibliográficas}

Valentim, M. L. P. (2002). Inteligência competitiva em organizações: dado, informação e conhecimento. DataGramaZero, 3(4). Recuperado de http://www.brapci.ufpr.br/brapci/_repositorio/2010/01/pdf f589d25523 0007468.pdf

Valentim, M. L. P. (2004). Gestão da informação e gestão do conhecimento: especificidades e convergências. Londrina: Infohome. Recuperado de http://www.ofaj.com.br/colunas conteudo.php?cod=88

Valentim, M. L. P. (Org.) (2007). Informação, conhecimento e inteligência organizacional. Marília: FUNDEPE.

Valentim, M. L. P. (Org.) (2008). Gestão da informação e do conhecimento no âmbito da ciência da informação. São Paulo: Polis: Cultura Acadêmica. 